\title{
Subtract Divisor Cordial Labeling
}

\author{
J.T. Gondalia, A.H. Rokad
}

Abstract-A subtract divisor cordial labeling is bijection $r: Z$ $\left(G^{+}\right) \rightarrow\left\{1,2, \ldots,\left|V\left(G^{+}\right)\right|\right\}$in such a way that an edge uv give the label 1 if $r(u)-r(v)$ is divisible by 2 otherwise give the label 0 , then absolute difference of number of edges having label 1 and 0 is at most 1. A graph which fulfill the condition of subtract divisor cordial labeling is called subtract divisor cordial graph. In given paper, we found ten new graphs satisfying the condition of subtract divisor cordial labeling.

AMS Subject classification number: $05 C 78$.

Index Terms-Wheel, helm, flower, star graph

\section{INTRODUCTION}

The graphs conceived are undirected, simple, finite and connected. We will have the basic symbols and expressions of graph theory as in [1]. For a dynamic survey of various graph labeling, we refer to Gallian [2].

The idea of sum divisor cordial labeling motivated us to introduce new idea called subtract divisor cordial labeling.

Definition 1.1: Let $\mathrm{G}^{+}$is a simple graph and $r: \mathrm{Z}\left(\mathrm{G}^{+}\right) \rightarrow$ $\left\{1,2, \ldots,\left|\mathrm{V}\left(\mathrm{G}^{+}\right)\right|\right\}$is a bijection. For every edge uv, give the label 1 if $2 \mid(r(\mathrm{u})-r(\mathrm{v}))$ and otherwise give the label 0 . The function $\mathrm{g}$ is called a subtract divisor cordial labeling if

$\left|e_{r}(1)-e_{r}(0)\right| \leq 1$. A graph which fulfill the condition of subtract divisor cordial labeling is called a subtract divisor cordial graph.

\section{MAIN RESULTS}

Theorem 2.1: The path $P_{n}$ is subtract divisor cordial graph. Proof Let $P_{n}$ is a path with gradual vertices $\left\{z_{1}, z_{2}, \ldots z_{n}\right\}$. Then $\mathrm{P}_{\mathrm{n}}$ is of size $n-1$ and order $n$.

Define the labeling $r: Z\left(P_{n}\right) \rightarrow\{1,2, \ldots \ldots ., n\}$ as below:

Case 1: $n$ is even.

$$
r\left(v_{i}\right)= \begin{cases}i-1 & \text { if } i \equiv 0(\text { modulo } 4) \\ i & \text { if } i \equiv 1,2 \text { (modulo } 4) \\ i+1 & \text { if } i \equiv 3 \text { (modulo } 4)\end{cases}
$$

Case 2: $n$ is odd. For $1 \leq i \leq n$ :

$$
r\left(v_{i}\right)= \begin{cases}i-1 & \text { if } i \equiv 3 \text { (modulo } 4) \\ i & \text { if } i \equiv 0,1 \text { (modulo } 4) \\ i+1 & \text { if } i \equiv 2(\text { modulo } 4)\end{cases}
$$

We notice that,

Revised Version Manuscript Received on April 12, 2019.

J.T. Gondalia, Research Scholar,RK University,Rajkot-360020, Gujarat, India ( E-mail: jatingondalia98@gmail.com)

A.H. Rokad, Department of Mathematics, School of Engineering,RK University,Rajkot-360020, Gujarat,

$$
\begin{aligned}
& e_{r}(1)= \begin{cases}\frac{n-2}{2} & n \text { even } \\
\frac{n-1}{2} & n \text { odd } .\end{cases} \\
& e_{r}(0)= \begin{cases}\frac{n}{2} & n \text { even } \\
\frac{n-1}{2} & n \text { odd } .\end{cases}
\end{aligned}
$$

Thus, $\left|\mathrm{e}_{\mathrm{r}}(1)-\mathrm{e}_{\mathrm{r}}(0)\right| \leq 1$

Thereby, the path $\mathrm{P}_{\mathrm{n}}$ is subtract divisor cordial graph.

Example 2.1: A subtract divisor cordial labeling of $\mathrm{P}_{9}$ can be seen in Figure 1

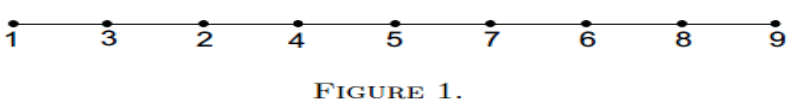

Theorem 2.2: Cycle $C_{n}(n \in N, n \geq 3)$ is subtract divisor cordial graph, excluding for $n \equiv 2$ (modulo 4 )

Proof: Let $Z\left(C_{n}\right)=\left\{z_{1}, z_{2}, \ldots, z_{n}\right\}$. Then the size of $C_{n}$ is $n$ and order is also $\mathrm{n}$.

Define the labeling $r: \mathrm{Z}\left(\mathrm{G}^{+}\right) \rightarrow\{1,2,3, \ldots, \mathrm{n}\}$ as below.

Case 1: For $\mathrm{n} \equiv 0,1,3$ ( modulo $_{4}$ ).

For $1 \leq \mathrm{i} \leq \mathrm{n}$ :

$$
r\left(v_{i}\right)=\left\{\begin{array}{lll}
i-1 & \text { if } i \equiv 3 \quad & \text { (modulo 4) } \\
i & \text { if } i \equiv 0,1 & \text { (modulo 4) } \\
i+1 & \text { if } i \equiv 2 \quad \text { (modulo 4) }
\end{array}\right.
$$

Case 2: For $n \equiv 2$ (modulo 4$)$

Then $C_{n}$ is not subtract divisor cordial graph. As per fulfillment of the edge condition for subtract divisor cordial graph it is necessary to give label 1 to $\frac{n}{2}$ edges and label 0 to $\frac{n}{2}$ edges from total $\mathrm{n}$ edges. The edge label will increase at least $\frac{n}{2}+1$ edges with label 1 and at most ${ }^{\frac{n}{2}-1}$ edges with label 0 from total $n$ edges. Therefore $\left|e_{r}(1)-e_{r}(0)\right|=2$ So the edge condition is go against for subtract divisor cordial graph.

Thereby $C_{n}$ is not subtract

Published By:

Blue Eyes Intelligence Engineering 
divisor cordial for $\mathrm{n} \equiv 2$ (modulo 4$)$.

From the look of above labeling pattern,

\begin{tabular}{|c|c|}
\hline Case of $\mathrm{n}$ & Edge condition \\
\hline $\mathrm{n} \equiv 0(\bmod 4)$ & $\mathrm{e}_{\mathrm{r}}(0)=\mathrm{e}_{\mathrm{r}}(1)=\frac{n}{2}$ \\
\hline $\mathrm{n} \equiv 1(\bmod 4)$ & $\mathrm{e}_{\mathrm{r}}(0)=\left\lfloor\frac{n}{2}\right\rfloor, \mathrm{e}_{\mathrm{r}}(1)=\left\lfloor\frac{n}{2}\right\rceil$ \\
\hline $\mathrm{n} \equiv 3(\bmod 4)$ & $\mathrm{e}_{\mathrm{r}}(0)=\left\lfloor\frac{n}{2}\right\rceil, \mathrm{e}_{\mathrm{r}}(1)=\left\lfloor\frac{n}{2}\right\rfloor$ \\
\hline
\end{tabular}

Evidently it fulfill the conduction $\left|\mathrm{e}_{\mathrm{r}}(1)-\mathrm{e}_{\mathrm{r}}(0)\right| \leq 1$.

Thereby $C_{n}$ is a subtract divisor cordial graph.

Example 2.2: Subtract divisor cordial labeling of $\mathrm{C}_{7}$ can be seen in Figure 2.



Figure 2.

Theorem 2.3: $C_{n}(n \in N, n \geq 4)$ having one chord is a subtract divisor cordial graph.

Proof: Let $z_{1}, z_{2}, \ldots, z_{n}$ is the gradual vertices of cycle $C_{n}$ and $e=z_{2} z_{n}$ is the chord $C_{n}$.

Then $C_{n}$ is of size $n+1$ and order $n$.

Define the labeling $\mathrm{r}: \mathrm{Z}\left(\mathrm{G}^{+}\right) \rightarrow\{1,2,3, \ldots, \mathrm{n}\}$ as below.

Case 1: For $\mathrm{n} \equiv 3$ (modulo 4 ).

$\mathrm{r}\left(v_{\mathrm{n}}\right)=\mathrm{n}-1, \mathrm{r}\left(\mathrm{v}_{\mathrm{n}-1}\right)=\mathrm{n}$

$$
\mathrm{r}\left(\mathrm{z}_{\mathrm{i}}\right)=\left\{\begin{array}{lll}
i+1 & \text { If } \mathrm{i} \equiv 3 & (\text { modulo } 4) \\
i-1 & \text { If } \mathrm{i} \equiv 0 & (\text { modulo } 4) \\
i & \text { If } \mathrm{i} \equiv 1,2 & \text { (modulo } 4), 1 \leq i \leq n-2
\end{array}\right.
$$

Case 2: For $\mathrm{n} \equiv 2,1,0(\bmod 4)$

$$
\mathrm{r}\left(\mathrm{z}_{\mathrm{i}}\right)= \begin{cases}i-1 & \mathrm{I} f \mathrm{i} \equiv 0 \quad \text { (modulo 4) } \\ i & \mathrm{I} f \mathrm{i} \equiv 1,2(\text { modulo } 4) \\ i+1 & \mathrm{I} f \mathrm{i} \equiv 3 \quad \text { (modulo 4), } 1 \leq i \leq n .\end{cases}
$$

From the look of above labeling pattern,

\begin{tabular}{|l|c|}
\hline \multicolumn{1}{|c|}{ Case of $\mathrm{n}$} & Edge condition \\
\hline $\mathrm{n} \equiv 0,2,3(\bmod 4)$ & $\mathrm{e}_{\mathrm{r}}(0)=\left\lfloor\frac{n+1}{2}\right\rfloor \mathrm{e}_{\mathrm{r}}(1)=\left\lceil\frac{n}{2}\right\rceil$ \\
\hline $\mathrm{n} \equiv 1(\bmod 4)$ & $\mathrm{e}_{\mathrm{r}}(0)=\mathrm{e}_{\mathrm{r}}(1)=\frac{n+1}{2}$ \\
\hline
\end{tabular}

Evidently it fulfill the condition $\left|e_{r}(1)-e_{r}(0)\right| \leq 1$.
Thereby, $\mathrm{C}_{\mathrm{n}}$ having one chord is a subtract divisor cordial graph.

Example 2.3: Subtract divisor cordial labeling of $\mathrm{C}_{8}$ having one chord can be seen in Figure 3.

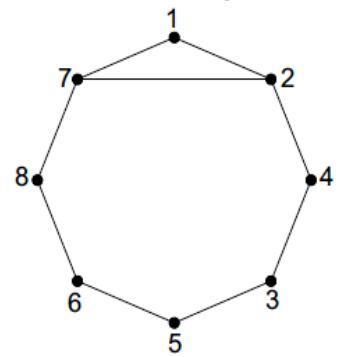

FiguRE 3.

Theorem 2.4: Cycle having twin chords $C_{n, 3}(n \in N, n \geq 5)$ is a subtract divisor cordial graph.

Proof: Let $z_{1}, z_{2}, \ldots, z_{n}$ is the gradual vertices of cycle $C_{n}$ and take $\mathrm{e}_{1}=\mathrm{z}_{\mathrm{n}} \mathrm{z}_{2}$ and $\mathrm{e}_{2}=\mathrm{z}_{\mathrm{n}} \mathrm{z}_{3}$ as the chords of $\mathrm{C}_{\mathrm{n}}$. $\left|\mathrm{E}\left(\mathrm{C}_{\mathrm{n}, 3}\right)\right|=$ $\mathrm{n}+2$ and $\left|\mathrm{V}\left(\mathrm{C}_{\mathrm{n}, 3}\right)\right|=\mathrm{n}$.

Define the labeling $\mathrm{r}: \mathrm{Z}\left(\mathrm{C}_{\mathrm{n}, 3}\right) \rightarrow\{1,2,3, \ldots, \mathrm{n}\}$ as below.

Case 1: For $\mathrm{n} \equiv 1,2$ (modulo 4$)$

For $1<\mathrm{i}<\mathrm{n}$ :

$$
r\left(v_{i}\right)=\left\{\begin{array}{lll}
i-1 & \text { if } \mathrm{i} \equiv 0 & \text { (modulo 4) } \\
i & \text { if } \mathrm{i} \equiv 1,2 & \text { (modulo 4) } \\
i+1 & \text { if } \mathrm{i} \equiv 3 & \text { (modulo 4) }
\end{array}\right.
$$

Case 2: For $\mathrm{n} \equiv 3$ (modulo 4$)$

For $1 \leq \mathrm{i} \leq \mathrm{n}-2$ :

$$
\begin{array}{r}
\mathrm{r}\left(\mathrm{z}_{\mathrm{n}}\right)=\mathrm{n}-1, \mathrm{r}\left(\mathrm{z}_{\mathrm{n}-1}\right)=\mathrm{n} \\
r\left(v_{i}\right)=\left\{\begin{array}{lll}
i-1 & \text { if } \mathrm{i} \equiv 0 & \text { (modulo 4) } \\
i & \text { if } \mathrm{i} \equiv 1,2 & \text { (modulo 4) } \\
i+1 & \text { if } \mathrm{i} \equiv 3 & \text { (modulo 4) }
\end{array}\right.
\end{array}
$$

Case 3: For $n \equiv 0$ (modulo 4).

For $1 \leq \mathrm{i} \leq \mathrm{n}$ :

$$
r\left(v_{i}\right)=\left\{\begin{array}{lll}
i-1 & \text { if } \mathrm{i} \equiv 3 \quad \text { (modulo 4) } \\
i & \text { if } \mathrm{i} \equiv 0,1 & \text { (modulo 4) } \\
i+1 & \text { if } \mathrm{i} \equiv 2 \quad \text { (modulo 4) }
\end{array}\right.
$$

From the look of above labeling pattern,

\begin{tabular}{|c|c|}
\hline Case of $\mathrm{n}$ & Edge condition \\
\hline $\mathrm{n} \equiv 0,2(\bmod 4)$ & $\mathrm{e}_{\mathrm{r}}(1)=\mathrm{e}_{\mathrm{r}}(0)=\frac{n+2}{2}$ \\
\hline $\mathrm{n} \equiv 1(\bmod 4)$ & $\mathrm{e}_{\mathrm{r}}(1)=\left\lceil\frac{n+2}{2}\right\rceil, \mathrm{e}_{\mathrm{r}}(0)=\left\lfloor\frac{n+2}{2}\right\rfloor$ \\
\hline $\mathrm{n} \equiv 3(\bmod 4)$ & $\mathrm{e}_{\mathrm{r}}(1)=\left\lfloor\frac{n}{2}\right\rfloor, \mathrm{e}_{\mathrm{r}}(0)=\left\lceil\frac{n}{2}\right\rceil$ \\
\hline
\end{tabular}

Evidently, it fulfill the condition $\left|\mathrm{e}_{\mathrm{r}}(1)-\mathrm{e}_{\mathrm{r}}(0)\right| \leq 1$. Thereby, $\mathrm{C}_{\mathrm{n}, 3}$ is a subtract divisor cordial graph.

Example 2.4: Subtract

Published By: 
divisor cordial labeling of $\mathrm{C}_{9,3}$ can be seen in Figure 4 .

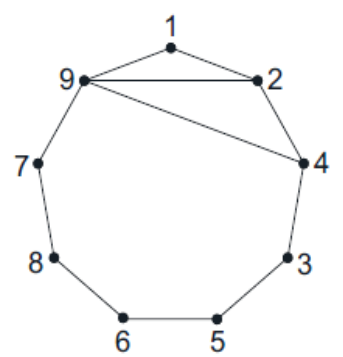

FIGURE 4.

Theorem 2.5: $\mathrm{C}_{\mathrm{n}}(1,1, \mathrm{n}-5)$ is a subtract divisor cordial graph, except for $n \equiv 3(\bmod 4)$

Proof: Let $z_{1}, z_{2}, \ldots, z_{n}$ is the gradual vertices of cycle $C_{n}$ and $\mathrm{e}_{1}=\mathrm{z}_{3} \mathrm{z}_{1}, \mathrm{e}_{2}=\mathrm{z}_{\mathrm{n}-1} \mathrm{z}_{3}$,

$e_{3}=z_{n-1} z_{1}$ be the chords of $C_{n} \cdot\left|E\left(C_{n}(1,1, n-5)\right)\right|=n+3, \mid V$ $\left(\mathrm{C}_{\mathrm{n}}(1,1, \mathrm{n}-5)\right) \mid=\mathrm{n}$.

Define the labeling $\mathrm{r}: \mathrm{Z}(\mathrm{G}) \rightarrow\{1,2,3, \ldots, \mathrm{n}\}$ as below.

Case 1: For $n \equiv 2$ (modulo 4 )

For $1 \leq \mathrm{i} \leq \mathrm{n}-2$ :

$\mathrm{r}\left(\mathrm{z}_{\mathrm{n}}\right)=\mathrm{n}-1, \mathrm{r}\left(\mathrm{z}_{\mathrm{n}-1}\right)=\mathrm{n}$.

$$
r\left(v_{i}\right)=\left\{\begin{array}{lll}
i-1 & \text { if } \mathrm{i} \equiv 3 \quad \text { (modulo } 4) \\
i & \text { if } \mathrm{i} \equiv 0,1 \text { (modulo } 4) \\
i+1 & \text { if } \mathrm{i} \equiv 2 \quad \text { (modulo } 4)
\end{array}\right.
$$

Case 2: For $\mathrm{n} \equiv 0,1($ modulo 4$)$

For $1 \leq \mathrm{i} \leq \mathrm{n}$ :

$$
r\left(v_{i}\right)=\left\{\begin{array}{lll}
i-1 & \text { if } \mathrm{i} \equiv 0 & \text { (modulo 4) } \\
i & \text { if } \mathrm{i} \equiv 1,2 & \text { (modulo 4) } \\
i+1 & \text { if } \mathrm{i} \equiv 3 & \text { (modulo } 4)
\end{array}\right.
$$

Case 3: For $\mathrm{n} \equiv 3$ (modulo 4 ).

Then cycle $C_{n}$ having triangle is not subtract divisor cordial graph.

In order to fulfillment of the edge condition for subtract divisor cordial graph it is necessary to give label 1 to $\frac{n+3}{2}$ edges and label 0 to $\frac{n+3}{2}$ edges from total $n+3$ edges. The edge label will increase at least $\frac{n+3}{2}+1$ edges with label 1 and at most $\frac{n+3}{2}-1$ edges with label 0 from total $n$ edges. Therefore $\left|e_{r}(1)-e_{r}(0)\right|=2$. So, the edge condition is go against for subtract divisor cordial graph.

Thereby, cycle havingh triangle is not subtract divisor cordial for $\mathrm{n} \equiv 3(\bmod 4)$

From the look of above labeling pattern,

\begin{tabular}{|c|c|}
\hline Case of $\mathrm{n}$ & Edge condition \\
\hline $\mathrm{n} \equiv 1(\bmod 4)$ & $\mathrm{e}_{\mathrm{r}}(1)=\mathrm{e}_{\mathrm{r}}(0)=\frac{n+3}{2}$ \\
\hline $\mathrm{n} \equiv 2(\bmod 4)$ & $\mathrm{e}_{\mathrm{r}}(1)=\left\lfloor\frac{n+3}{2}\right\rceil, \mathrm{e}_{\mathrm{r}}(0)=\left\lfloor\frac{n+3}{2}\right\rfloor$ \\
\hline $\mathrm{n} \equiv 0(\bmod 4)$ & $\mathrm{e}_{\mathrm{r}}(1)=\left\lfloor\frac{n+3}{2}\right\rfloor, \mathrm{e}_{\mathrm{r}}(0)=\left\lfloor\frac{n+3}{2}\right\rceil$ \\
\hline
\end{tabular}

Evidently, it fulfill the condition $\left|\mathrm{e}_{\mathrm{r}}(1)-\mathrm{e}_{\mathrm{r}}(0)\right| \leq 1$.

Thereby, $\mathrm{C}_{\mathrm{n}}(1,1, \mathrm{n}-5)$ is a subtract divisor cordial graph.

Example 2.5: Subtract divisor cordial labeling of cycle

\section{$\mathrm{C}_{10}(1,1,3)$ with triangle can be seen in Figure 5.}

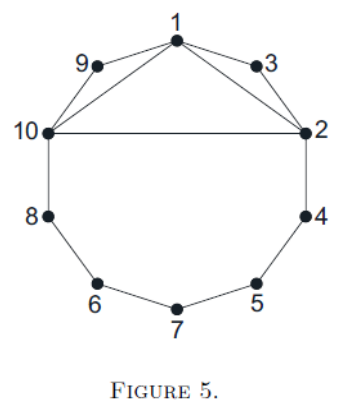

Theorem 2.6: $\mathrm{W}_{\mathrm{n}}$ is a subtract divisor cordial graph except for $\mathrm{n} \equiv 3$ (modulo 4$)$.

Proof: Let $z_{1}, z_{2}, \ldots, z_{n}$ is the rim vertices and $v_{0}$ be the central vertex of $\mathrm{W}_{\mathrm{n}}$.

Also order and size of the wheel graph is $n+1$ and $2 n$ respectively.

Define the labeling $r: \mathrm{V}\left(\mathrm{W}_{\mathrm{n}}\right) \rightarrow\{1,2,3, \ldots \ldots, \mathrm{n}+1\}$ as below.

Case 1: For $n \equiv 2($ modulo 4$)$

For $1 \leq \mathrm{i} \leq \mathrm{n}$,

$r\left(\mathrm{z}_{0}\right)=2$

$$
r\left(v_{i}\right)=\left\{\begin{array}{lll}
i+2 & \text { if } \mathrm{i} \equiv 0 & \text { (modulo } 4) \\
i & \text { if } \mathrm{i} \equiv 1 & \text { (modulo 4) } \\
i+1 & \text { if } \mathrm{i} \equiv 2,3 & \text { (modulo } 4)
\end{array}\right.
$$

Case 2: For $\mathrm{n} \equiv 0,1($ modulo 4$)$

For $1 \leq \mathrm{i} \leq \mathrm{n}$ :

$r\left(\mathrm{z}_{0}\right)=1$.

$$
r\left(v_{i}\right)= \begin{cases}i+2 & \text { if } \mathrm{i} \equiv 2(\operatorname{modulo} 4) \\ i & \text { if } \mathrm{i} \equiv 3(\operatorname{modul} 4) \\ i+1 & \text { if } \mathrm{i} \equiv 0(\operatorname{modul} 4)\end{cases}
$$

Case 3: $\mathrm{n} \equiv 3$ (modulo 4 )

Then $\mathrm{W}_{\mathrm{n}}$ is not subtract divisor cordial graph.

In order to fulfillment of the edge condition for subtract divisor cordial graph it is necessary to give label 1 to $n$ edges and label 0 to $n$ edges from total $2 \mathrm{n}$ edges. The edge label will increase at least $n-1$ edges with label 1 and at most $n+1$ edges with label 0 from total $2 n$ edges. Therefore, $\mid e_{r}(1)$ $\mathrm{e}_{\mathrm{r}}(0) \mid=2$. So the edge condition is go against for subtract divisor cordial graph.

Thereby $\mathrm{W}_{\mathrm{n}}$ is not subtract divisor cordial, for $\mathrm{n} \equiv$ $3(\bmod 4)$.

From the look of above labeling pattern,

\begin{tabular}{|c|c|}
\hline Case of $n$ & Edge condition \\
\hline $\mathrm{n} \equiv 2,1,0(\bmod 4)$ & $\mathrm{e}_{\mathrm{r}}(1)=\mathrm{e}_{\mathrm{r}}(0)=\mathrm{n}$ \\
\hline
\end{tabular}

Evidently, it fulfill the condition $\left|\mathrm{e}_{\mathrm{r}}(1)-\mathrm{e}_{\mathrm{r}}(0)\right| \leq 1$.

Thereby, $\mathrm{W}_{\mathrm{n}}$ is a subtract divisor cordial graph.

Example 2.6. Subtract divisor cordial labeling of wheel $\mathrm{W}_{6}$ can be seen in Figure 6. 


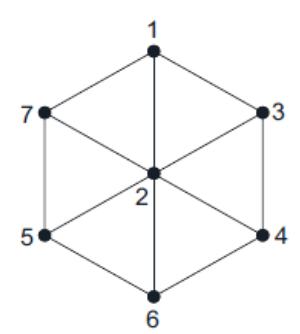

Figure 6 ,

Theorem 2.7:Helm $\mathrm{H}_{\mathrm{n}}$ is a subtract divisor cordial graph.

Proof: Let $v_{0}$ is the central vertex, $z_{1}, z_{2}, \ldots, z_{n}$ is the vertices of degree 4 and $\mathrm{y}_{1}, \mathrm{y}_{2}, \ldots, \mathrm{y}_{\mathrm{n}}$ be the pendant vertices of $\mathrm{H}_{n}$. Also order and size of the helm graph is $2 n+1$ and $3 \mathrm{n}$ respectively.

Define the labeling $r: \mathrm{V}\left(\mathrm{H}_{\mathrm{n}}\right) \rightarrow\{1,2,3, \ldots, 2 \mathrm{n}+1\}$ as below.

$\mathrm{r}\left(\mathrm{z}_{0}\right)=1$.

To label the residual vertices, conceive the below cases.

Case 1: $n \equiv 1,3(\bmod 4)$.

$\mathrm{r}\left(\mathrm{z}_{\mathrm{n}}\right)=2 \mathrm{n}+1$

$\mathrm{r}\left(\mathrm{z}_{2 \mathrm{i}-1}\right)=4 \mathrm{i}-1 ; 1 \leq \mathrm{i} \leq^{\frac{n-1}{2}}$.

$\mathrm{r}\left(\mathrm{z}_{2 \mathrm{i}}\right)=4 \mathrm{i}-2 ; 1 \leq \mathrm{i} \leq \frac{n-1}{2}$

$\mathrm{r}\left(\mathrm{y}_{\mathrm{i}}\right)=\mathrm{g} \quad\left(\mathrm{v}_{\mathrm{i}}\right)+2 ; 1 \leq \mathrm{i} \leq \mathrm{n}-1$.

$\mathrm{r}\left(\mathrm{y}_{\mathrm{n}}\right)=2 \mathrm{n}$.

Case 2: $\mathrm{n} \equiv 2,0$ (modulo 4 ).

$\mathrm{r}\left(\mathrm{y}_{\mathrm{i}}\right)=\mathrm{r}\left(\mathrm{z}_{\mathrm{i}}\right)+2 ; 1 \leq \mathrm{i} \leq \mathrm{n}$.

$\mathrm{r}\left(\mathrm{z}_{2 \mathrm{i}-1}\right)=4 \mathrm{i}-1 ; 1 \leq \mathrm{i} \leq \frac{n}{2}$

$\mathrm{r}\left(\mathrm{z}_{2 \mathrm{i}}\right)=4 \mathrm{i}-2 ; 1 \leq \mathrm{i} \leq \frac{n}{2}$

From the look of the above labeling pattern,

\begin{tabular}{|c|c|}
\hline Case of $\mathrm{n}$ & Edge condition \\
\hline $\mathrm{n} \equiv 2,0(\bmod 4)$ & $\mathrm{e}_{\mathrm{r}}(1)=\mathrm{e}_{\mathrm{r}}(0)=\frac{3 n}{2}$ \\
\hline $\mathrm{n} \equiv 1,3(\bmod / 4)$ & $\mathrm{e}_{\mathrm{r}}(1)=\left\lceil\frac{3 n}{2}\right\rceil, \mathrm{e}_{\mathrm{r}}(0)=\left\lfloor\frac{3 n}{2}\right\rfloor$ \\
\hline
\end{tabular}

Evidently, it fulfill the condition $\left|\mathrm{e}_{\mathrm{r}}(1)-\mathrm{e}_{\mathrm{r}}(0)\right| \leq 1$.

Thereby $\mathrm{H}_{\mathrm{n}}$ is a subtract divisor cordial graph.

Example 2.7. Subtract divisor cordial labeling of helm $\mathrm{H}_{8}$ can be seen in Figure 7.



Figure 7 .
Theorem 2.8: $\mathrm{fl}_{\mathrm{n}}$ is a subtract divisor cordial graph.

Proof: Let $\mathrm{v}_{0}$ is the central vertex $\mathrm{z}_{1}, \mathrm{z}_{2}, \ldots, \mathrm{z}_{\mathrm{n}}$ is the vertices of degree 4 and $y_{1}, y_{2}, \ldots, y_{n}$ be the vertices of degree 2 in $\mathrm{fl}_{\mathrm{n}}$.

$\left|\mathrm{E}\left(\mathrm{fl}_{\mathrm{n}}\right)\right|=4 \mathrm{n} \square \square \square \square \mathrm{V}(\mathrm{D} \square=2 \mathrm{n}+1$.

Define the labeling $\mathrm{r}: \mathrm{Z}\left(\mathrm{fl}_{\mathrm{n}}\right) \stackrel{\square}{\square}\{1,2,3, \ldots . .2 \mathrm{n}+1\}$ as below.

$\mathrm{r}\left(\mathrm{z}_{0}\right)=1$

$\mathrm{r}\left(\mathrm{z}_{\mathrm{i}}\right)=2 \mathrm{i}, 1 \leq \mathrm{i} \leq \mathrm{n}$.

$\mathrm{r}\left(\mathrm{y}_{\mathrm{i}}\right)=2 \mathrm{i}+1 ; 1 \leq \mathrm{i} \leq \mathrm{n}$.

From the look of the above labeling pattern, we have

\begin{tabular}{|c|c|}
\hline Case of $\mathrm{n}$ & Edge condition \\
\hline $\mathrm{n} \equiv 3,2,1,0(\bmod 4)$ & $\mathrm{e}_{\mathrm{r}}(1)=\mathrm{e}_{\mathrm{r}}(0)=2 \mathrm{n}$ \\
\hline
\end{tabular}

Evidently it fulfill the condition $\left|\mathrm{e}_{\mathrm{r}}(1)-\mathrm{e}_{\mathrm{r}}(0)\right| \leq 1$.

Thereby, $\mathrm{fl}_{\mathrm{n}}$ is a subtract divisor cordial graph.

Example 2.8: subtract divisor cordial labeling of $\mathrm{fl}_{5}$ can be seen in Figure 8.

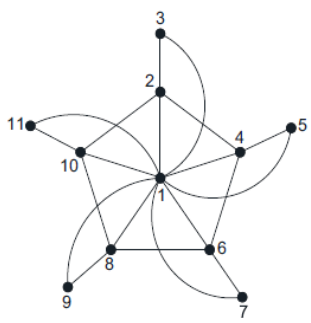

Figure 8

Theorem 2.9: The gear $G_{n}$ is subtract divisor cordial graph.

Proof: Let $\mathrm{G}^{+}=\mathrm{G}_{\mathrm{n}}$. Let $\mathrm{Z}(\mathrm{G})=\left\{\mathrm{z}, \mathrm{y}_{\mathrm{i}}\right.$, $\left.\mathrm{zi}: 1 \leq \mathrm{i} \leq \mathrm{n}\right\}$ and $\mathrm{E}(\mathrm{G})=\left\{\mathrm{zz}_{\mathrm{i}}, \mathrm{z}_{\mathrm{i}} \mathrm{y}_{\mathrm{i}}: 1 \leq \mathrm{i} \leq \mathrm{n} ; \mathrm{u}_{\mathrm{i}} \mathrm{v}_{\mathrm{i}+1}: 1 \leq \mathrm{i} \leq \mathrm{n}-1 ; \mathrm{y}_{\mathrm{n}} \mathrm{z}_{1}\right\}$. Also order and size of the gear graph is $2 n+1$ and $3 n$ respectively.

Define the labeling $r: \mathrm{Z}(\mathrm{G}) \rightarrow\{1,2, \ldots, 2 \mathrm{n}+1\}$ as below:

$\left.\mathrm{r}(\mathrm{z})=1 ; \mathrm{r}\left(\mathrm{z}_{2 \mathrm{i}}-1\right)=4 \mathrm{i}-1 ; 1 \leq \mathrm{i} \leq \leq^{\left\lceil\frac{n}{2}\right.}\right\rceil$

$\mathrm{r}\left(\mathrm{z}_{2 \mathrm{i}}\right)=4 \mathrm{i} ; 1 \leq \mathrm{i} \leq\left\lfloor\frac{n}{2}\right\rfloor$

$\mathrm{r}\left(\mathrm{y}_{2 \mathrm{i}-1}\right)=4 \mathrm{i}-2 ; 1 \leq \mathrm{i} \leq\left\lceil\frac{n}{2}\right\rceil$

$\mathrm{r}\left(\mathrm{y}_{2 \mathrm{i}}\right)=4 \mathrm{i}+1 ; 1 \leq \mathrm{i} \leq\left\lfloor\frac{n}{2}\right\rfloor$

From the look of the above labeling pattern,

\begin{tabular}{|c|c|}
\hline Case of $\mathrm{n}$ & Edge condition \\
\hline $\mathrm{n} \equiv 3,2,1,0(\bmod 4)$ & $\mathrm{e}_{\mathrm{r}}(1)=\left\lfloor\frac{3 n}{2}\right\rfloor, \mathrm{e}_{\mathrm{r}}(0)=\left\lceil\frac{3 n}{2}\right\rceil$ \\
\hline
\end{tabular}

Evidently it fulfill the condition $\left|\mathrm{e}_{\mathrm{r}}(1)-\mathrm{e}_{\mathrm{r}}(0)\right| \leq 1$.

Thereby $G_{n}$ is a subtract divisor cordial graph.

Example 2.9: A subtract divisor cordial labeling of $\mathrm{G}_{7}$ can be seen in Figure 9. 


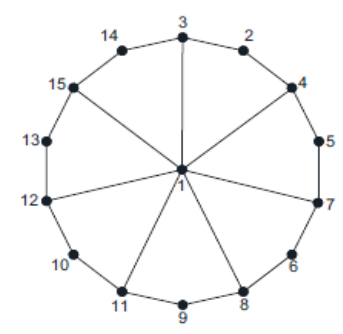

Figure 9.

Theorem 2.10: Star $K_{1, \mathrm{n}}$ is subtract divisor cordial graph. Proof. Let $\left(\mathrm{Z}_{1}, \mathrm{Z}_{2}\right)$ be the bipartition of $\mathrm{K}_{1, \mathrm{n}}$ with $\mathrm{Z}_{1}=\mathrm{y}$ and $\mathrm{Z}_{2}=\mathrm{y}_{1}, \mathrm{y}_{2}, \ldots, \mathrm{y}_{\mathrm{n}}$. Let $\mathrm{E}\left(\mathrm{K}_{1, \mathrm{n}}\right)=\left\{\mathrm{yy}_{\mathrm{i}}: 1 \leq \mathrm{i} \leq \mathrm{n}\right\}$. Then $\mathrm{K}_{1, \mathrm{n}}$ is of size $n$ and order $n+1$.

Define the labeling $\mathrm{r}: \mathrm{Z}\left(\mathrm{K}_{1, \mathrm{n}}\right) \rightarrow\{1,2, \ldots, \mathrm{n}+1\}$ as below:

$$
\begin{aligned}
& \mathrm{r}(\mathrm{y})=1, \\
& \mathrm{r}\left(\mathrm{y}_{\mathrm{i}}\right)=\mathrm{i}+1,1 \leq \mathrm{i} \leq \mathrm{n} .
\end{aligned}
$$

We notice that,

$$
\begin{aligned}
& e_{r}(1)= \begin{cases}\frac{n}{2} & n \text { even } \\
\frac{n-1}{2} & n \text { odd }\end{cases} \\
& e_{r}(0)= \begin{cases}\frac{n}{2} & \text { neven } . \\
\frac{n+1}{2} & \text { n odd } .\end{cases}
\end{aligned}
$$

Evidently it fulfill the condition $\left|\mathrm{e}_{\mathrm{r}}(1)-\mathrm{e}_{\mathrm{r}}(0)\right| \leq 1$.

Thereby $\mathrm{K}_{1,7}$ is a subtract divisor cordial graph.

Example 2.10. A subtract divisor cordial labeling of $\mathbf{K}_{1,7}$ can be seen in Figure 10.



Figure 10.

\section{CONCLUSION}

We introduce here new idea of subtract divisor cordial labeling. This will add new dimension to the research work in the area connecting two branches graph labeling and number theory. Here we have investigated ten new graph families which acknowledge subtract divisor cordial labeling. The results proved in this paper are novel. Examples are provided at the end of each theorem for wider grasping of the pattern of labeling defined in each theorem. To explore some new subtract divisor cordial graphs is an open problem.

\section{REFERENCES}

1. F. Harary, Graph theory, Addision-wesley, Reading, MA (1969)

2. J. A. Gallian, A dynamic survey of graph labeling, The Elec. J. of Combi. 19 (2012), \#DS6 1 - 260.

3. I. Cahit, Cordial Graphs: A weaker version of graceful and Harmonic Graphs, Ars Combin. 23(1987), 201-207.

4. Amit H. Rokad and Gaurang V. Ghodasara, Divisor Cordial Labeling Of Cycle Related Graphs, Int. J. for Research in Applied Sci. Eng. Tech. Vol. 3 (X), October 2015.

5. A. Lourdusamy and F. Patrick, Subtract divisor cordial graphs, Proyecciones J. of Math. Vol. 35(1), March 2016.

6. D.G. Adalja1, G. V. ghodasara, Subtract divisor cordial Labeling of Ring Sum of a Graph With Star Graph,Int. J. of Comp. Sci. and Eng. Vol.-6 (6), Jun 2018.

7. D.G. Adalja1, G. V. ghodasara, Subtract divisor cordial Labeling of Snakes Related Graphs, J. Of Comp. and Math. Sci. Vol.9(7), July 2018 . 